\title{
Variable Conjunct Agreement in Qaraqalpaq
}

\author{
Sarah Asinari \& Si Kai Lee*
}

\begin{abstract}
This paper examines a unique Variable Conjunct Agreement (VCA) pattern in Qaraqalpaq. In this language, the second or third person pronoun can undergo conjunct agreement with the verb from either the first or last conjunct. This agreement pattern is disrupted in the presence of any first person pronoun, regardless of whether the pronoun is within the ConjP. We use a multidominant structure to represent coordination in Qaraqalpaq. We propose that a Speaker head is required to merge the ConjP with the rest of the structure. This Speaker head is also required to license the [+Speaker] feature of the first person pronoun. This competition prevents first person pronouns and VCA from co-occurring in the same sentence; the only possibility in the relevant cases is full subject agreement.
\end{abstract}

Keywords. Qaraqalpaq; First Conjunct Agreement; Last Conjunct Agreement; multidominance; late parallel merge

1. Introduction. Qaraqalpaq (also known as Karakalpak) is a Turkic language spoken primarily in Karakalpakstan, Uzbekistan. The default word order in Qaraqalpaq is SOV, with the verb undergoing agreement with the subject. We present novel data pertaining to this agreement pattern when the subject in question is a conjunction phrase (ConjP). ${ }^{1}$ In particular, we demonstrate that in such constructions, the verb has the option of undergoing agreement with either the first or the second conjunct (1-2), a pattern which we are calling Variable Conjunct Agreement (VCA). ${ }^{2}$
(1) ol hám sen seker-de-ń 3SG and 2SG jump-PST-2SG
'S/he and you jumped.'
(2) ?sen hám ol seker-de-ń 2SG and 3SG jump-PST-2SG 'You and s/he jumped.'

Agreement with either conjunct, rather than the ConjP as a whole, has been studied extensively as either First or Last Conjunct Agreement patterns (e.g. Aoun et al. 1994, 1999; Marušič et al. 2007; Benmamoun et al. 2009; Bošković 2009). However, languages that allow conjunct agreement are usually consistent with respect to which of the two conjuncts is privileged within a particular syntactic configuration. That Qaraqalpaq allows for both first conjunct agreement (FCA) and last conjunct agreement (LaCA) within a single syntactic configuration is therefore surprising, providing a window of insight into the underlying mechanisms which drive Conjunct Agreement more generally.

Furthermore, we highlight an interesting complication in the elicited data, namely that the agreement patterns in (1-2) are blocked when in the presence of a first person pronoun (3-4).

\footnotetext{
* The data in this paper comes from our consultant, Elnara Klicheva. Thank you for sharing your beautiful language with us. This material is based upon work supported by the program in Science of Learning \& Art of Communication at the University of Connecticut, which is supported by the National Science Foundation under Grant DGE1747486. Authors: Sarah Asinari, University of Connecticut (sarah.asinari@uconn.edu) \& Si Kai Lee, University of Connecticut (si_kai.lee@uconn.edu).

${ }^{1}$ The data presented here follow under the assumption that this is a conjunction of two NPs, and not CPs showing agreement, which are then elided. This is not entirely discounted, however, and is left to further research.

${ }^{2}$ Comparatively, Last Conjunct Agreement is more acceptable than First Conjunct Agreement in Qaraqalpaq, however, FCA is still acceptable, resulting in a marginal difference.
} 


\section{(3)}
(4) a. *sen hám men seker-de-ń 2SG and 1SG jump-PST-2SG 'You and I jumped'
b. *men hám sen seker-de-m $1 \mathrm{SG}$ and $2 \mathrm{SG}$ jump-PST-1SG 'I and you jumped'

b. *sen hám men seker-de-m 2SG and 1SG jump-PST-1SG 'You and I jumped'

The two key desiderata for our analysis are thus (i) a system for conjunct agreement that is independent of linear order, since the 2 nd person pronoun can participate in agreement independently from either conjunct; and (ii) the ability to account for the 1st person blocking effect.

To this end, we propose that VCA in Qaraqalpaq is the result of the late parallel merge of the non-agreeing conjunct (cf. Soltan (2007) for a late-merge account of First Conjunct Agreement in Arabic), which results in the presence of a multidominant structure within the derivation which cannot be spelt out as is (Citko 2005). We argue that the 1st person interruption effects observed are a byproduct of competition between the rescue mechanism for this multidominant structure, and a 1st person licensing requirement present in the language, which is independent of coordination.

This paper is laid out as follows: Section 2 will briefly sketch the basic agreement patterns in Qaraqalpaq, Section 3 will lay out the Variable Conjunct Agreement patterns, and Section 4 breaks down our analysis for Late Parallel Merge in Qaraqalpaq. Section 5 concludes.

2. Agreement Patterns in Qaraqalpaq. This section will briefly sketch out the agreement patterns available in Qaraqalpaq. Nouns in Qaraqalpaq are not gendered; verbs, therefore, do not exhibit gender agreement. Thus, (overt) verbal agreement is only with person and number.

2.1. Base Agreement PATterns. Verbal predicates in Qaraqalpaq have distinct overt agreement morphemes for 1st and 2nd person agreement in both the singular and the plural, while the third person agreement uniformly manifests as a zero ending (5-6).

(6)

\section{(5)}
a. men seker-de-m
1SG jump-PST-1SG
'I jumped.'
b. sen seker-de-ń
2sG jump-PST-2sG
'You (sg) jumped.'
c. ol seker-de- $\varnothing$
3SG jump-PST-3SG
'S/he jumped.'

a. biz seker-de-k

1PL jump-PST-1PL

'We jumped.'

b. siz seker-de-ńez

2PL jump-PST-2PL

'You (pl) jumped.'

c. sizler seker-de-ńez(-ler)

2PL.HON jump-PST-2PL(-HON)

'You (honorific) jumped.'

d. olar seker-de- $\varnothing$

3PL jump-PST-3PL

'They jumped.'

A similar pattern exists for other predicate types, such as, with 1st and 2nd person agreement being realised by distinct overt morphemes, and 3rd person agreement corresponding to a zero ending in both the singular and the plural. The full verbal agreement paradigm is presented in (9). 
(7)

a. men jaxsı shıpaker-man

1SG good doctor-1SG

'I am a doctor.'

b. sen jaxsı shipaker-san

2SG good doctor-2SG

'You are a doctor.'

c. ol jaxsı shipaker- $\varnothing$

3SG good doctor-3SG

'S/he is a doctor.'

\begin{tabular}{|c|c|c|}
\hline & SG & PL \\
\hline $1 \mathrm{st}$ & $-\mathrm{m}$ & $-\mathrm{K}^{a}$ \\
\hline 2nd & $-n ́$ & $-n ́ E z(l e r)$ \\
\hline 3rd & $\varnothing$ & $\varnothing$ \\
\hline
\end{tabular}

Table 1. Verbal Agreement Morphemes

${ }^{a}-\mathrm{K}$ and $-\mathrm{E}$ represent underspecified consonants or vowels respectively.
(8)
a. biz jaxsı shıpaker-mez
1PL good doctor-1 PL
'We are good doctors.'
b. siz jaxsı shipaker-sez
2PL good doctor-2PL
'You (pl) are good doctors.'
c. olar jaxsı shipaker- $\varnothing$
3PL good doctor-3PL
'They are good doctors.'

\begin{tabular}{|c|c|c|}
\hline & SG & PL \\
\hline 1st & -man & $-\mathrm{mEz}$ \\
\hline 2nd & -sań & $-\mathrm{sEz}$ \\
\hline 3rd & $\varnothing$ & $\varnothing$ \\
\hline
\end{tabular}

Table 2. Adj/N Predicate Agr Morphemes

2.2. Conjunct Agreement Patterns. Ostensibly, Qaraqalpaq has two options when it comes to the coordination of nominal phrases, either using the lexical item 'menen/penen' or the lexical item 'hám. However, only the latter ('hám') appears to be a true coordinator, with 'menen/penen' behaving like a comitative with respect to agreement possibilities. As such, we put 'menen/penen' aside, instead focusing our attention on 'hám' constructions, where the agreement patterns of interest surface. We begin by sketching out the basic agreement paradigms with ConjP subjects.

The standard verbal agreement with a coordinated subject is summative in nature, meaning that the $\varphi$-features of the conjuncts are considered cumulatively. To illustrate, in (10), where the ConjP contains both a 2 nd person and 1 st person pronoun, the agreement that manifests on the verb is 1 st person plural.

$$
\begin{aligned}
& \text { sen hám men seker-de-k } \\
& \text { 2SG and 1SG jump-PST-1PL } \\
& \text { 'You and I jumped.' }
\end{aligned}
$$

If there is only one pronoun in the ConjP, like in (11), the agreement matches the pronoun and not the proper name, resulting in 2nd person plural, since proper names unsurprisingly count as 3 rd person. For instance, in (11), the person agreement is with the 2 nd person pronoun, and number is obligatorily plural with conjuncts containing a proper name.

(11) sen hám Hórzija seker-de-ńez

2SG and Horzija jump-PST-2PL

'You and Horzija jumped.' 
3. Variable Agreement Paradigms. VCA in Qaraqalpaq is observed only when the two conjuncts are $2 \mathrm{nd}$ and $3 \mathrm{rd}$ person elements. If a 1st person pronoun enters the derivation at any point, these VCA patterns are blocked entirely. This section will spell out the combinations and VCA patterns present in Qaraqalpaq. We will also cover the extent to which 1st person pronouns disrupt agreement.

To begin, we note that there are other languages that have been documented to exhibit both First and Last Conjunct Agreement patterns, such as Bosnian/Croatian/Serbian, which show FCA with postverbal subjects and $\mathrm{LaCA}$ with preverbal subjects (for the full paradigms and a unified analysis of the SC facts, see Bošković 2009). Note, however, that while this appears to be a VCA pattern much like what we are reporting for Qaraqalpaq, in that both FCA or LaCA are available in a single language, the two paradigms are distinct in that the distribution of FCA and LaCA is complementary within languages like SC, but overlapping in Qaraqalpaq, i.e. VCA implicates that FCA and LaCA are in free alternation.

3.1. 2ND Person Agreement. Second person pronouns can undergo agreement with the verb whether they are the first or last conjunct. Only one conjunct showing verbal agreement we will call 'partial agreement'. In (12), the verb bears 2 nd person singular agreement with the 2 nd person pronoun in the last conjunct position; the 2 nd person pronoun can also control agreement on the verb from the first position (2, repeated below as 13$)$.

(12) ol hám sen seker-de-ń

3SG and 2SG jump-PST-2SG

'S/he and you jumped.' ?sen hám ol seker-de-ń

2SG and 3SG jump-PST-2SG

'You and s/he jumped.'

Note that second person agreement can sometimes appear even when there is phonological material between the last conjunct and the verb (14).

(14) ol hám sen tez seker-de-ń

3SG and 2SG quickly jump-PST-2SG

'S/he and you quickly jumped.'

This, however, is inconsistent, since certain elements do appear to disrupt agreement (15) (cf. Benmamoun et al. 2009; as shown for Tsez). ${ }^{3}$

*ol hám sen berye esle-de-ń

3SG and 2SG together work-PST-2SG

'S/he and you worked together.'

Regardless, the fact that only some phonological material can disrupt VCA and the fact that VCA can hold between the first conjunct and the verb, even as the second conjunct serves as a linear intervenor, suggests that VCA in Qaraqalpaq is not a PF phenomenon (more generally, there is no linear adjacency effect for either first or last conjunct agreement).

\footnotetext{
${ }^{3}$ If the verbal agreement is 2 nd person plural, the sentence is grammatical. This would be full agreement with the verb displaying cumulative agreement, which is entirely standard for many languages, including Qaraqalpaq.
} 
3.2. 3RD Person Agreement. VCA in Qaraqalpaq can also be established with a 3rd person conjunct, though this results in null agreement on the verb, given the agreement paradigms that hold in the language. As with the 2nd person conjuncts, VCA with 3rd person conjuncts can hold from either the first conjunct or second conjunct position $(16-17)$.

(16) a. ol hám sen ketap-t1 1laqtır-dı- $\varnothing$

3SG and 2SG book-ACC throw-PST-3SG

'S/he and you threw the book.'

b. sen hám ol ketap-tı 1laqtır-d1- $\varnothing$

2SG and 3SG book-ACC throw-PST-3SG

'You and s/he threw the book.'

a. ?ol hám sen jaxsı shipaker- $\varnothing$

3SG and 2SG good doctor-3SG

'S/he and you are good doctors.'

b. sen hám ol jaxsı shipaker- $\varnothing$

2SG and 3SG good doctor-3SG

'You and s/he are good doctors.'

3.3. 1St PERSON DisRuption EFFects. First person pronouns always disrupt the Variable Conjunct Agreement seen with second person pronouns, regardless of which conjunct they are in (18). With a first person pronoun present, the second person pronoun cannot undergo partial agreement as the second conjunct; the only option is full first person plural agreement.
a. *men hám sen seker-de-ń
$1 \mathrm{SG}$ and $2 \mathrm{SG}$ jump-PST-2SG
'I and you jumped'
b. *men hám sen seker-de-m $1 \mathrm{SG}$ and $2 \mathrm{SG}$ jump-PST-1SG
'I and you jumped'

Not only do they prevent second person from undergoing partial agreement, but the first person pronoun cannot undergo agreement itself with the verb (19).
a. *sen hám men seker-de-ń $2 \mathrm{SG}$ and $1 \mathrm{SG}$ jump-PST-2SG
'You and I jumped'
b. *sen hám men seker-de-m $2 \mathrm{SG}$ and $1 \mathrm{SG}$ jump-PST-1SG 'You and I jumped'

Second person singular partial agreement is disrupted even if the first person pronoun is a possessor within the ConjP, which means that is not a conjunct itself (20).

a. ?seneń ažapa-ń hám sen shipaker-seń 2SG.POSS sister-2ND.POSS and 2SG doctor-2SG

'Your sister and you are doctors.'

b. *meneń ažapa-m hám sen shipaker-seń

1sG.POSS sister-1SG.POSS and 2SG doctor-2SG

'My sister and you are doctors'

Perhaps most surprising is the fact that the first person pronoun doesn't need to be within the subject ConjP at all to disrupt partial agreement. In (21a), the first person pronoun is an indirect 
object; this still prevents 2 nd person singular agreement on the verb. Note that this blocking effect can be pinpointed to the 1st person pronoun; changing the indirect object to a third person pronoun, as in (21b), restores the possibility of second person agreement. Otherwise, full 2 nd person plural agreement is required. This is especially peculiar given that, for a subject agreement language, something other than the subject has an effect on agreement.

a. *ol hám sen maǵan tabaq-t1 1laqtır-di-ń

3SG and 2SG 1SG.DAT bowl-ACC throw-PST-2SG

'S/he and you threw a bowl at me'

b. ?ol hám sen oǵan tabaq-tı 1laqtır-di-ń

3SG and 2SG 3RD.DAT bowl-ACC throw-PST-2SG

'S/he and you threw a bowl at him/her'

4. Late Parallel Merge. As noted in Section 1, an account that seeks to cover the reported Qaraqalpaq paradigms has the following desiderata: (i) the ability to capture partial agreement with either conjunct, not just specifically first or specifically last, in the same syntactic configuration, and (ii) the ability to account for the novel 1st person disruption effect that extends beyond simple argument structure.

There are many analyses of conjunct agreement in the literature (Aoun et al. 1994, 1999; Marušič et al. 2007; Benmamoun et al. 2009; Bošković 2009; among many others). We will expand upon one of these, namely Soltan's (2007) account of FCA in Arabic, which we will adopt as the first ingredient for our analysis.

Soltan (2007) argues that the FCA patterns in Standard Arabic (SA), where postverbal subjects in an VS configuration allow FCA (22), while SV orders require full agreement (23), arises as a result of late merge of the non-agreeing conjunct.

VS First Conjunct Agreement
a. 3aa?a Zayd-un wa Hind-u
came-3 SG.MASC Zayd-NOM.MASC and Hind-NOM.FEM
'Zayd and Hind came.'
b. 3aa?a-t Hind-u wa Zayd-un
came-3SG.FEM Hind-NOM.FEM and Zayd-NOM.MASC
'Hind and Zayd came.'

(23) SV Full Conjunct Agreement
a. Zayd-un
wa Hind-u
zaa?aa
Zayd-NOM.MASC and Hind-NOM.FEM came-3DU.MASC
'Zayd and Hind came.'
b. *Zayd-un wa Hind-u zaa?a/zaa?a-t
Zayd-NOM.MASC and Hind-NOM.FEM came-3SG.MASC/came-3 SG.FEM
'Zayd and Hind came.'

Under Soltan's analysis, the first conjunct, sans the rest of the ConjP, is first base-generated in the structure. The $\varphi$-agreement probe on T, having no other targets available, probes into this first conjunct, finds the relevant $\varphi$-feature-bearing head and enters into a head-head Agreement 
relationship with the first NP conjunct. ${ }^{4}$ The ConjP is then Late Merged postcyclically. Since Agree has already taken place, the plural specification of the ConjP is not reflected in the agreement pattern, thus yieding FCA.

We propose that VCA in Qaraqalpaq is similarly the result of late merge of the non-agreeing conjunct. However, we diverge from Soltan's analysis in one key aspect, namely in that we assume a Spec-head configuration for agreeement. ${ }^{5}$

The upshot of this is that consequently, late merge must take place at SpecTP rather than in SpecvP, as Soltan proposes for SA, for the reason that the relevant agreement relationship is established at SpecTP, and late-merge of the non-agreeing conjunct has to minimally be later than agreement. This yields the word order facts for Qaraqalpaq, whilst preserving the theoretical underpinnings of Soltan's analysis (i.e. late merge as the driving mechanism for conjunct agreement).

Though this is technically not a break from Soltan's analysis, we argue that the late merger step actually proceeds in a parallel merge fashion (Citko 2005). This technical implementation of late merge, we argue, allows us to address the second desideratum, namely, the 1st person disruption effects observed in Qaraqalpaq, for reasons that will become clearer once we establish how the 1st person pronoun is privileged, in the sense that it disrupts VCA in this language.

4.1. FirSt PERSON LICENSING. To begin, we must first acknowledge that there is something that sets 1 st person apart from 2nd and 3rd persons respectively, since it alone (i) disrupts VCA in Qaraqalpaq, and (ii) can disrupt VCA even from a more deeply embedded position, or indeed from a ConjP-external position altogether.

One approach to framing the distinction of 1 st person pronouns from 2 nd and 3 rd person pronouns is to do so featurally (Hale 1973; Harley \& Ritter 2002); accordingly, this interruption effect can also be framed as arising from the presence of a [+Speaker] feature unique to 1st person pronouns.

The lack of locality with respect to the disruption effects observed indicates that they cannot be a result of the [+Speaker] interfering with the establishment of the agreement relationship, for the following reasons: first, if the 1st person pronoun is a conjunct in itself, then simply late merging it should circumvent any sort of intervention effects with the $\varphi$-probe. In other words, we would not expect 1st person conjuncts, which can, in principle, be late merged, to interrupt VCA. For the same reason, 1st person possessors in the non-agreeing conjunct cannot be expected to disrupt VCA. Second, 1st person indirect objects, which are eminently outside of the domain of subject agreement, also disrupt VCA. Taken in conjunction, these facts therefore indicate that the locus of the 1st person disruption effect cannot be agreement proper.

Instead, drawing upon work by Speas \& Tenny (2003), Sundaresan (2018), and Charnavel (2021), amongst others, which have looked at phenomena sensitive to person features such as logophoric licensing, etc., we suggest that the [+Speaker] feature has an independent licensing

\footnotetext{
${ }^{4}$ Head-head Agreement relationships are not a standard mechanism for Agreement. While Soltan does propose this for SA, we will adopt one of the more standard practices of Spec-head Agreement below.

${ }^{5}$ Soltan crucially requires that agreement in SA is established in head-head configurations rather than Spec-head to account for the limited distribution of FCA in SA; full (summative) agreement with the ConjP in SV configurations actually involves head-head agreement with a pro situated in SpecvP which is coreferential to the ConjP base-generated in SpecTP, an A position. The agreeing pro bears the $\varphi$-features that result in summative agreement by means of this coreferentiality. FCA patterns in SV configurations in SA are thus ruled out because the coreferentiality between pro and ConjP forces pro to always inherit plurality, ergo summative agreement is always realized.
} 
requirement which is satisfied in a Spec-head configuration with a functional head at the left periphery of the clause. ${ }^{6}$ In particular, we adopt Poletto's (2000) Speaker head. Poletto (2000) proposes the existence of this functional projection on the basis of an asymmetry that holds between 1st person and $2 \mathrm{nd} / 3$ rd persons in the northern Italian dialects; while all other person combinations have a corresponding subject clitic, 1st person subject clitics are unattested. Under Poletto's (2000) analysis, the SpeakerP projection is immediately above the TP projection, with the verb(al complex) moving to the Speaker head; for the purposes of our analysis, we remain agnostic with respect to the rollup movement of the verbal complex to this additional projection.

Abstracting away from head-finality, the clausal spine of Qaraqalpaq is represented in (24).

Qaraqalpaq clausal spine:

[SpeakerP Speaker [TP T [ $\left.\left.\left.{ }_{\nu \mathrm{P}} v[\mathrm{VP} \mathrm{V}]\right]\right]\right]$

We argue that the 1st person disruption effect is due to this independent licensing requirement of $[+$ Speaker] interfering with the independent structural requirements imposed by parallel merge.

4.2. Parallel Merge and Multidominance. The operation of Parallel Merge combines properties from both internal merge and external merge; in Citko (2005), a node which is (externally) merged in one position can then be (internally) merged again. To illustrate, in (25), $\gamma$ first merges with $\alpha$ and then is also merged to $\beta$, such that $\gamma$ ends up with two mother nodes.
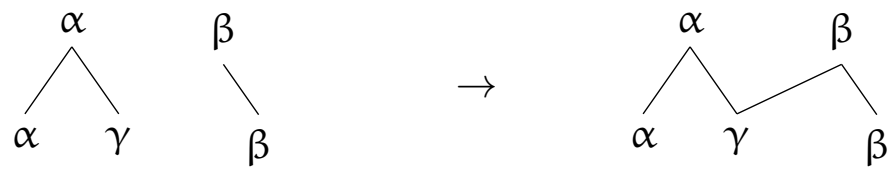

As Citko (2005) notes, such multidominant structures are inherently incompatible with Kayne's (1994) Linear Correspondence Axiom (LCA). Multidominant structures, which are symmetrical, run afoul of the LCA, which asserts that there is a strict correspondence between linear precedence and asymmetric c-command. Citko, drawing from Chomsky (1995) and Moro (2000), proposes that this inherent tension can be resolved if we assume that the LCA is essentially a PF-condition, such that it is checked at Spell-Out rather than derivationally; consequently, parallel merge structures can therefore be LCA-obeying if the symmetric multidominant structures introduced by parallel merge are resolved derivationally prior to Spell-Out, i.e. through the establishment of asymmetry between the two elements.

In essence, our proposal for VCA constructions in Qaraqalpaq is that a conjunct, either first or last, is first base-generated in SpecvP, before moving to SpecTP, where it enters an agreement relationship with $\mathrm{T}$. After that, the other conjunct is late merged with the agreeing conjunct in a parallel merge fashion, though the derivation proceeds slightly differently depending on whether the agreeing conjunct is the first or the last conjunct. In either case, the late parallel merge that introduces the other conjunct results in a symmetric multidominant structure that cannot be linearized. However, this symmetry can be resolved through the internal merge of the ConjP to the

\footnotetext{
${ }^{6}$ There are two possible options for the nature of the [+Speaker] feature: one is that it's simply an uninterpretable feature, which forces movement to its specifier, another option is that there is a feature on the first person pronoun that needs valuation, rather than checking for interpretability. The authors, at this time, do not have data in support for one over the other, and, as such, leave it for future research.
} 
left peripheral Speaker head ${ }^{7}$, which forms part of the basic clausal spine in Qaraqalpaq, thus forcing asymmetry between the problematic ConjP and TP (26).

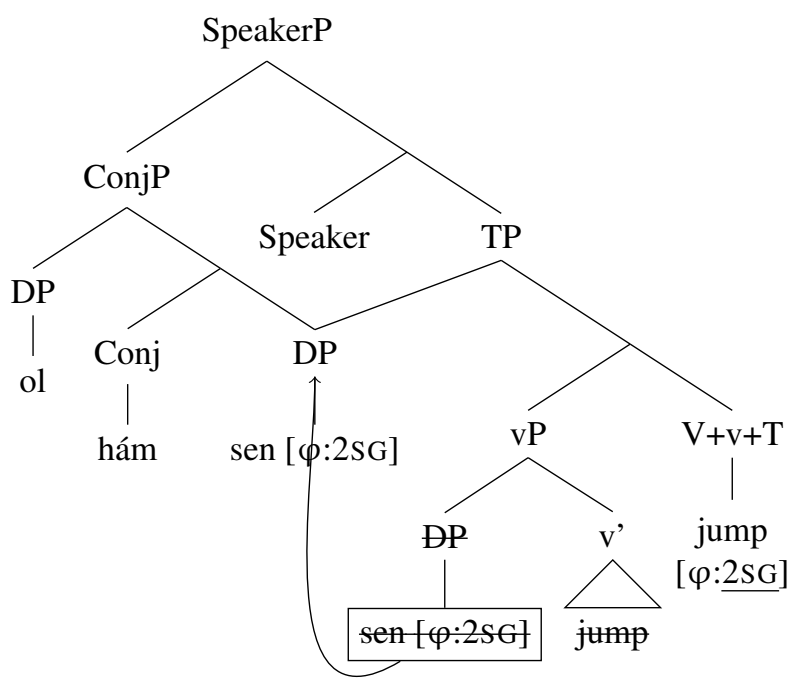

This will be broken down step by step in the following subsections for both first and last conjunct agreement.

4.3. Last Conjunct Agreement. To explain the Last Conjunct Agreement patterns, like in (12) repeated here as (27), we posit that the agreeing 2 nd person pronoun is merged in the structure before the ConjP. This NP has unvalued features and T has uninterpretable features that need to be checked. T is a probe that seeks the c-commanded goal NP (Chomsky 1995, 2001). The NP then moves to SpecTP and enters a Spec-head agreement relationship with the combined V+V+T head. This results in 2 nd person singular agreement being realized on the verb (28).

ol hám sen seker-de-ń

3SG and 2SG jump-PST-2SG

'S/he and you jumped.'

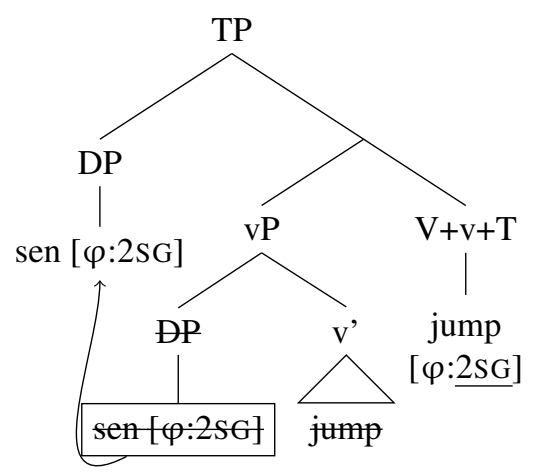

At this point in the derivation, the Conj head is parallel-merged with the already merged 2nd person DP 'sen' currently situated in SpecTP. Conj then projects, forming a multidominant structure, and then takes the first conjunct as its specifier.

\footnotetext{
${ }^{7}$ Note that our presentation of the Speaker head as being head-initial in the tree representations is purely for exposition.
} 
(29)

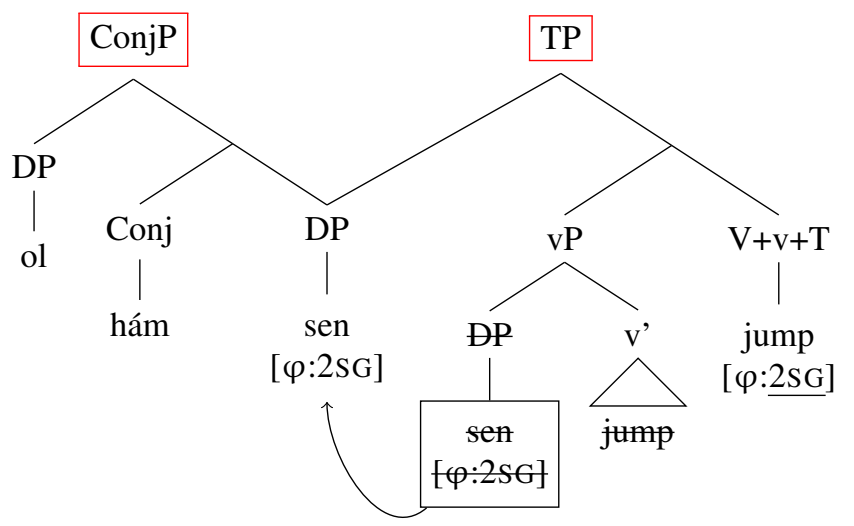

At this stage in the derivation, multidominance has not been resolved, i.e. a higher projection is needed in order to establish asymmetry for linearization reasons. Recall, however, that the Qaraqalpaq clausal spine includes the functional head Speaker; the derivation is thus able to converge by means of having Speaker take TP as its complement and ConjP as its specifier, eliminating the symmetry problem. With the multidominance resolved, an LCA-obeying Last Conjunct Agreement structure is successfully sent to Spell-Out.

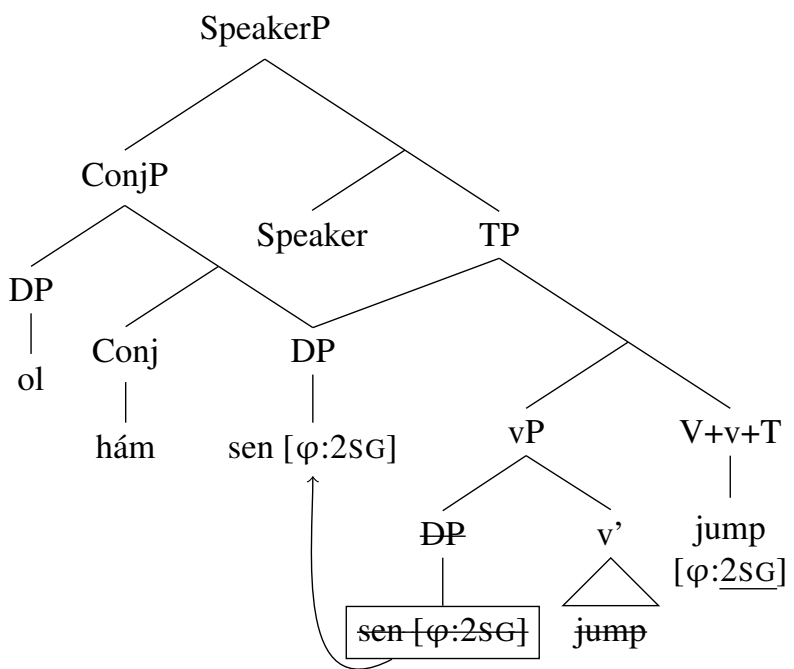

4.4. First Conjunct Agreement. The First Conjunct Agreement patterns, like (13) repeated here as (31), can be accounted for in a similar fashion.
?sen hám ol seker-de-ń
2SG and 3SG jump-PST-2SG
'You and s/he jumped.'

The first conjunct is merged in SpecvP and proceeds to SpecTP where it enters an agreement relation with the complex $\mathrm{V}+\mathrm{v}+\mathrm{T}$ head. This results in the realization of 2 nd person singular agreement on the verbal complex (32). 


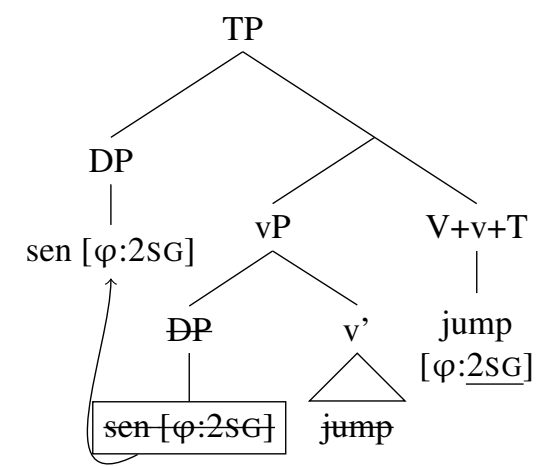

The conjunction is merged with the second conjunct in a separate workspace before undergoing late parallel merge to take the first conjunct DP as its specifier (33).

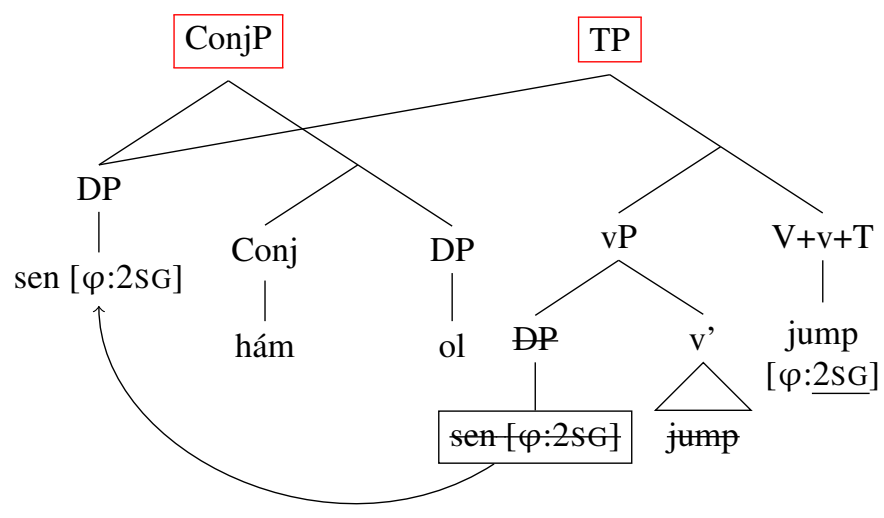

As with the LaCA derivation, we are left with a multidominant structure at this stage of the derivation; as before, the Speaker head is available to take the TP as its complement and ConjP as its specifier, thereby establishing antisymmetry and allowing the structure to be linearized, thus yielding the LCA-obeying FCA construction in (34).

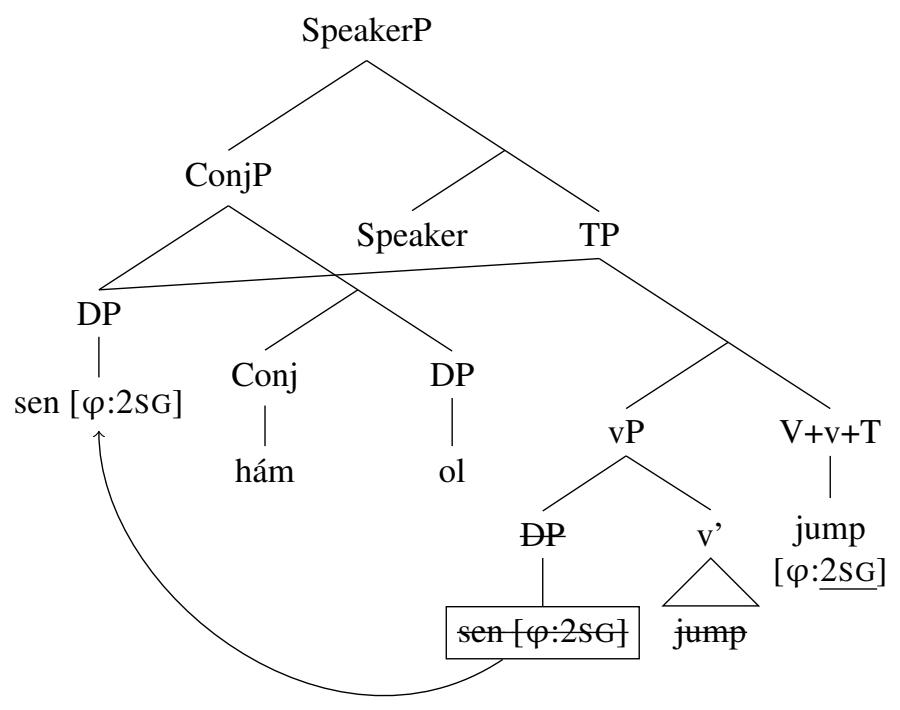


4.5. Deriving 1st Person Disruption. These VCA patterns break down in the presence of a 1st person pronoun anywhere in the sentence, even if it's outside of the ConjP proper, because the [+Speaker] feature introduced by the 1st person pronoun needs to be in a Spec-head relation with the Speaker head to be checked. ${ }^{8}$ The 1 st person pronoun also obligatorily only undergoes covert movement, while the ConjP overtly occupies the SpecSpeakerP. In other words, the multidominant structure introduced by parallel merge in a VCA construction and 1st person pronouns in Qaraqalpaq compete for the same structural position, i.e. SpecSpeakerP, albeit for different reasons. This results in the complementary distribution of 1st person pronouns and VCA in the language, since each bleeds the other.

In (35), the Speaker head has taken the ConjP as its specifier, thus resolving the issue of multidominance. However, the [+Speaker] feature on the 1st person pronoun is unlicensed, and the derivation crashes as a result.

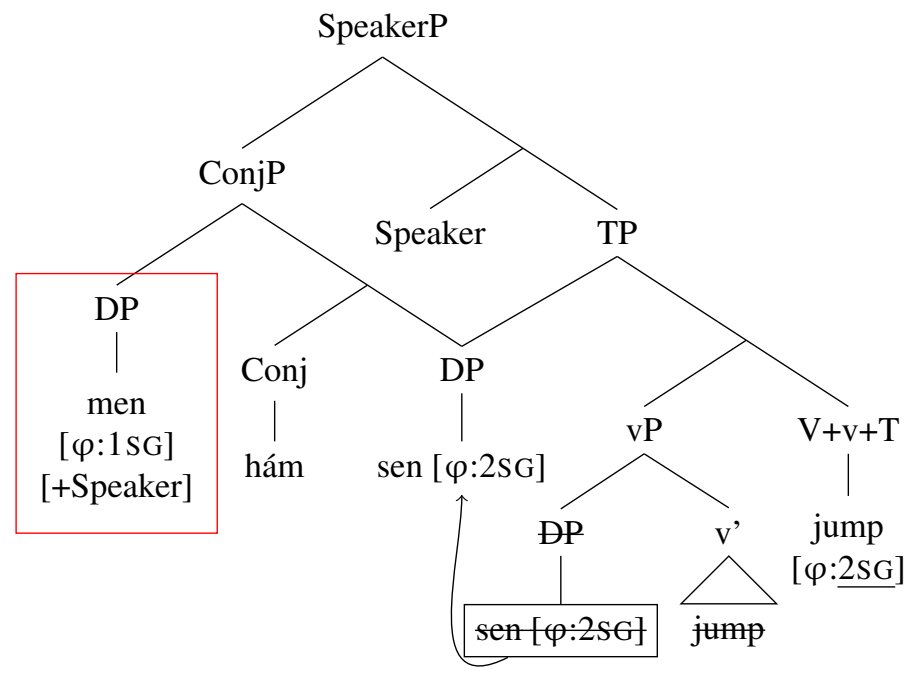

Conversely, in (36), the [+Speaker]-bearing 1st person pronoun has moved to SpecSpeakerP, where it is licensed. The structure, however, is not LCA-obeying, in that the asymmetry between ConjP and TP is not established; the linearization algorithm thus fails to proceed and the derivation again crashes as a result.

A question that arises at this point is: can a single clause host multiple 1st person pronouns? Since each 1st person pronoun would contain a [+Speaker] feature that requires checking by Speaker, one might expect us to predict that a single clause can only ever host a single 1st person pronoun. However, this prediction is patently false (37).

${ }_{8}^{8}$ Just as we assume for T, the checking of the [+Speaker] feature is assumed to occur in a Spec-head configuration with the pronoun moving covertly. 


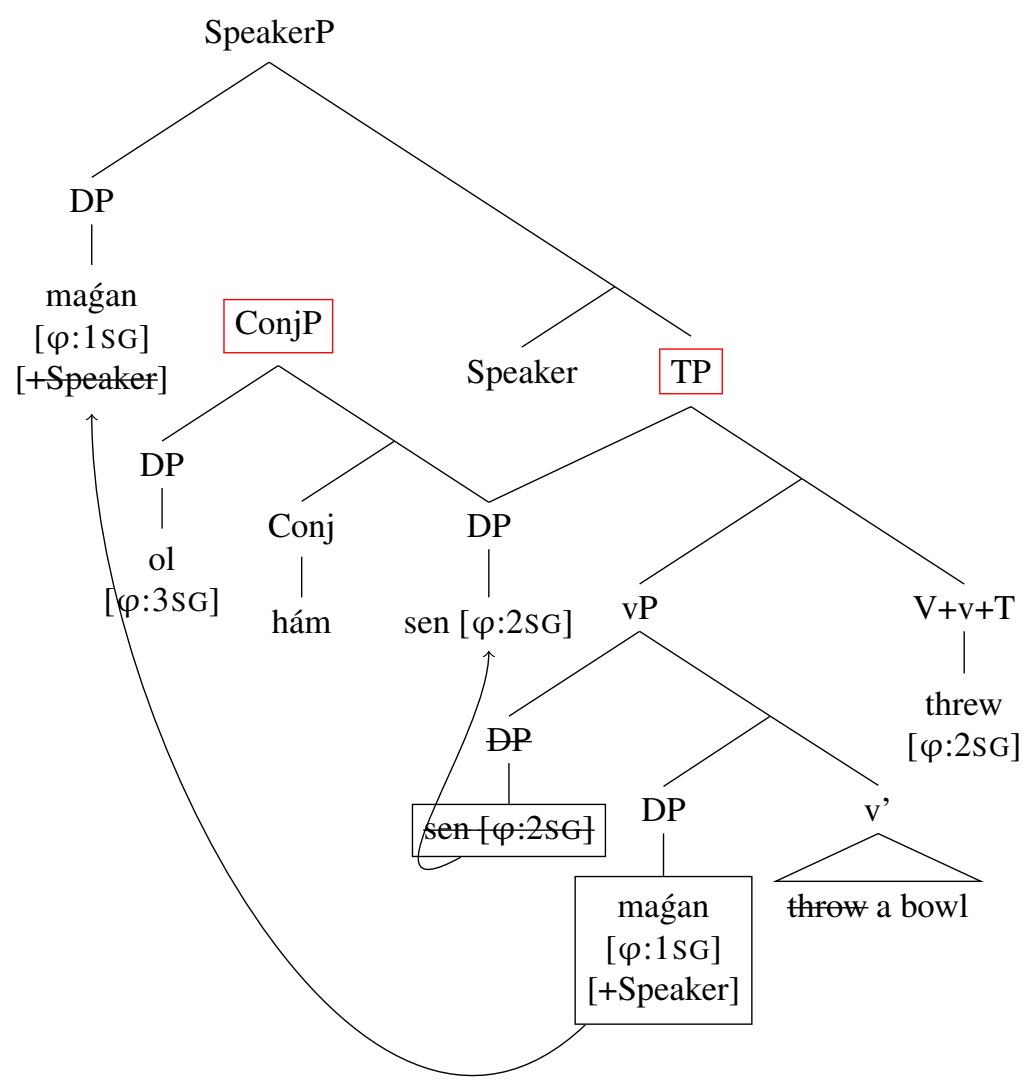

(37) meneń ažapa-m hám men shipaker-mez 1SG.POSS sister-1SG.POSS and 1SG doctor-1PL

'My sister and I are doctors'

To account for this, we suggest that a parallel to the movement of the [+Speaker] can be found in that of multiple $w h$-fronting. Just as covert $w h$-movement is assumed to generate multiple specifiers in the case of multiple $w h$-questions in single $w h$-fronting languages (see Richards 1997; Pesetsky 2000), the merger of multiple 1st person pronouns is able to create multiple specifiers in the left edge where the relevant Spec-head configuration is established. The ability to create additional specifier positions is crucially not extended to the (re)merger of ConjP, since it is not featurally motivated, its occupation of SpecSpeakerP instead having a last-resort flavor.

To rule out the derivational possibility where [+Speaker]-driven movement creates additional specifiers following the internal merge of the ConjP for the resolution of multidominance, we suggest that the covert movement of [+Speaker] to SpecSpeakerP for checking always precedes the internal merge of ConjP into SpecSpeakerP, such that movement of any number of [+Speaker] features always bleeds the ability of a multidominant structure to converge. This is in line with Citko (2005); since LCA is only checked at Spell-Out, and the internal merge of ConjP is purely for the satisfaction of the LCA, we can expect it to follow featurally driven movements such as that of the $[+$ Speaker] feature.

Another question that can be asked at this point is: why don't we see 1st person disruption effects in other languages which have conjunct agreement? We note that the patterns we have re- 
ported for Qaraqalpaq are highly complex, and our proposed analysis has attempted to account for them as resulting from the confluence of (i) the content of the left edge in Qaraqalpaq (i.e. the presence of the functional Speaker head), (ii) its availability for eliminating symmetry resulting from parallel merge as a last resort, and (iii) a licensing requirement of the [+Speaker] feature. Within the system which we have established, crosslinguistic variation with respect to any of these three factors would result in a paradigm in which 1st person disruption effects are no longer predicted (we leave it open which of these options are actually instantiated).

4.6. Summary. We have presented here a novel pattern of Variable Conjunct Agreement from Qaraqalpaq, where there is free alternation with respect to which conjunct, last or first, undergoes conjunct agreement with the verb. However, both of these patterns are disrupted by the presence of a first person pronoun in any part of the sentence. To account for this, we proposed that VCA in Qaraqalpaq results from the late parallel merge of the non-agreeing conjunct, such that the agreeing conjunct, either first or last, is merged and agreement, finding only this conjunct, is established with it, thus yielding VCA. The rest of the ConjP is then late parallel-merged postagreement, creating a non-LCA-compliant multidominant structure, which is rescued when the Speaker head is obligatorily merged as part of the clausal spine in Qaraqalpaq, taking the TP as its complement, and ConjP as its specifier, thus establishing asymmetry to the satisfaction of the LCA. However, this Speaker head is also required to license the [+Speaker] feature of first person pronoun(s), which covertly move to form a Spec-head configuration with the Speaker head. The 1st person disruption effects are thus a consequence of the competition between the [+Speaker] feature and the multidominant structure generated by the late parallel merge of the non-agreeing conjunct.

5. Conclusion. The novel data provided here from Qaraqalpaq provides additional evidence that outside factors (like 1st person indirect objects) can interfere with agreement relations. While there are other additional confounding factors for Variable Conjunct Agreement in Qaraqalpaq that were not presented here, the generalization of the 1st person intervention effect in the language serves as a foundation for further exploration into the complicated phenomenon. Qaraqalpaq is an outlier language in that neither conjunct is inherently privileged (e.g. like syntactic ordering of conjuncts in BCS), rather it is the 1st person pronoun features which are privileged for agreement, which is atypical behavior for languages exhibiting FCA/LaCA. The nature of VCA in Qaraqalpaq raises further questions as to the nature of FCA/LaCA cross-linguistically.

\section{References}

Aoun, Joseph, Elabbas Benmamoun \& Dominique Sportiche. 1994. Agreement, word order, and conjunction in some varieties of arabic. Linguistic inquiry 195-220.

Aoun, Joseph, Elabbas Benmamoun \& Dominique Sportiche. 1999. Further remarks on first conjunct agreement. Linguistic inquiry 30(4). 669-681.

Benmamoun, Elabbas, Archna Bhatia \& Maria Polinsky. 2009. Closest conjunct agreement in head final languages. Linguistic variation yearbook 9(1). 67-88.

Bošković, Željko. 2009. Unifying first and last conjunct agreement. Natural Language \& Linguistic Theory 27(3). 455-496.

Charnavel, Isabelle. 2021. Logophoricity, perspective, and reflexives. Annual Review of Linguistics 7. http://dx.doi.org/10.1146/annurev-linguistics-030220-085846.

Chomsky, Noam. 1995. The minimalist program. MIT Press 20th edn. 
Chomsky, Noam. 2001. Derivation by phase (mitopl 18). Ken Hale: A Life is Language 1-52. Citko, Barbara. 2005. On the nature of merge: External merge, internal merge, and parallel merge. Linguistic Inquiry 36(4). 475-496.

Hale, Kenneth Locke. 1973. Person marking in Walbiri. In Steven A. Anderson \& Paul Kiparski (eds.), A Festschrift for Morris Halle, New York: Holt.

Harley, Heidi \& Elizabeth Ritter. 2002. Person and number in pronouns: A feature-geometric analysis. Language 78(3). 482-526.

Kayne, Richard. 1994. The antisymmetry of syntax Linguistic inquiry monographs. MIT Press.

Marušič, Franc, Andrew Nevins \& Amanda Saksida. 2007. Last-conjunct agreement in slovenian. In Formal approaches to slavic linguistics, vol. 15, 210-227.

Moro, A. 2000. Dynamic antisymmetry Linguistic inquiry monographs. MIT Press.

Pesetsky, David. 2000. Phrasal movement and its kin Linguistic Inquiry Monographs. MIT Press.

Poletto, Cecilia. 2000. The higher functional field : Evidence from northern italian dialects Oxford studies in comparative syntax. Oxford University Press, USA.

Richards, Norvin. 1997. What moves where when in which language?: Massachusetts Institute of Technology dissertation.

Soltan, Usama. 2007. On agree and postcyclic merge in syntactic derivations: First conjunct agreement in standard arabic revisited. Perspectives on Arabic linguistics 19. 191-213.

Speas, Peggy \& Carol Tenny. 2003. Configurational properties of point of view roles. Asymmetry in Grammar: Volume 1: Syntax and semantics 315-344. http://dx.doi.org/10.1075/la.57.15spe.

Sundaresan, Sandhya. 2018. Perspective is syntactic: evidence from anaphora. Glossa: a journal of general linguistics 3(1). 128. http://dx.doi.org/http://doi.org/10.5334/gjgl.81. 